\title{
Why are Noise Elements so Silent?
}

\section{DAVID DUBBINK}

The Noise Elements requirements contained in the guidelines for General Plans in the State of California represent an important step towards ensuring that urban development meets higher standards of environmental quality. David Dubbink discusses how the European initiatives can provide California with a model of how to craft noise maps that provide accurate and understandable information.

Recently the European Parliament directed its member states to prepare noise maps. Maps are to be produced for metropolitan centers and for land near airports, motorways and rail lines. The idea of having noise maps is familiar to California planners. They've been a required feature of General Plans since 1972. However, there is a quantum difference between the mapping effort now underway in Europe and the California noise maps. They say that learning about another culture gives you insights into your own. This is certainly the case for noise control strategies. A quick look at the European initiatives tells us why the California Noise Elements are so little used.

\section{Mapping}

The European maps are readable and accurate. Figures 1 and 2 show how a typical California plan's noise map compares to one produced in Germany. The differences are more than aesthetic. Germany's shows the outlines of individual houses. This level of detail is typical for a European noise map. Noise exposure is indicated using a color gradient, which is easier for people to understand than the usual noise contour maps. The German map is an interactive, web-served document that can be zoomed, scrolled and queried. ${ }^{1}$ The noise levels are shown in selectable color layers for day and for night - and for different noise sources such as roadways and rail lines. With this web page map, you can also click on any location and a popup box appears giving the appropriate noise level at the selected point. Such map displays can even be linked to digital recordings to deliver actual acoustic experiences appropriate to the selected site. ${ }^{2}$

There is also a quantum difference in the accuracy of the maps. The German map is based on noise estimation technologies that consider topography, shielding and reflections. If you look closely at the color gradations near the structures you see that the buildings cast an "acoustic shadow". Although it doesn't show in plan view, noise exposure is projected over the building's surface, too. Each building face and each floor level of the structure are separately evaluated. Small black and white discs are scattered over the German map representing locations where the noise levels were measured using a portable monitoring system mounted in a small trailer. You can click on one of these disks and see a photo of the trailer standing in the neighborhood along with a numeric table showing both the measured and estimated noise levels. The level of map accuracy appears to be on the order of plus or minus two decibels - at the threshold of detectable difference.

By contrast, the noise estimation technology used to produce the California map includes no topography. There is no shielding and no reflections. There are no buildings. The California noise map appears to have been created by drawing lines at a fixed distance from the centerline of major roadways. The contour lines end at the city limits. At best, the California map is a crude indicator of places where noise might be an issue. It doesn't depict noise levels with anything approximating the
David Dubbink, Ph.D., AICP, was a professor in the Cal Poly's CRP Department from 1989 to 2006, when he retired. $\mathrm{He}$ is the director of the consulting firm Noise Management Inc.

Note: $A$ version of this article appeared in the APA's Cal Planner; MayJune 2006.

${ }^{1}$ The address of the interactive source site is www.noiserus.com. The color map example and images on following pages were provided by the acoustic consultancy ACCON (engineering bureau for sound and vibration technology in Greifenberg/Germany) www.accon.de. The images are copyrighted by ACCON.

2 The Interactive Sound Information System developed by the author is an example of an interactive mapping system linked to acoustic examples. See www. noisemanagement.com 


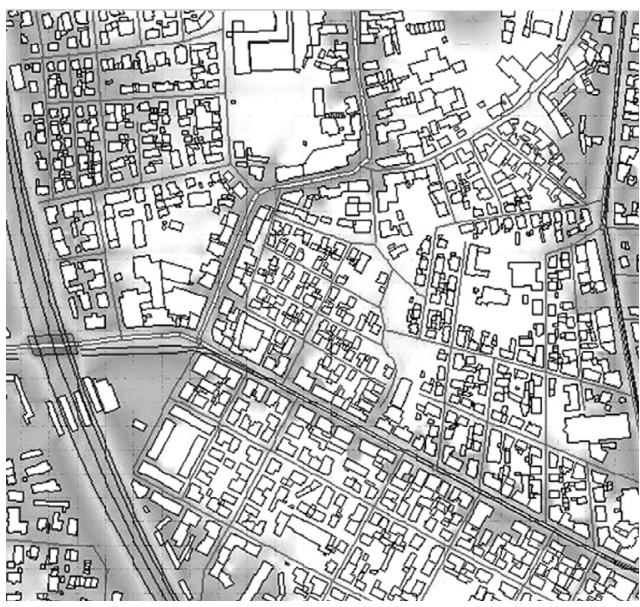

Figures 1 \& 2

Noise maps from Germany (above; original in color) and California (below).

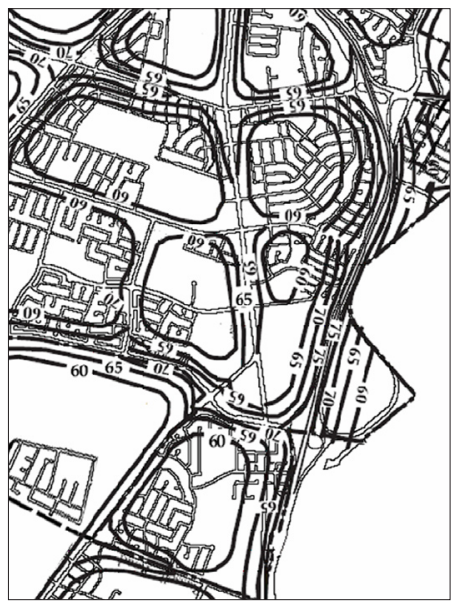

precision of the German map. The German map looks better, is more informative and is decidedly more accurate than its California counterpart.

\section{The Tyranny of Standards}

Every city in the state has a noise map that resembles the example of the California Noise Map shown in Figure 2. There's no coincidence in this; the maps conform to very explicit OPR guidelines.

There was a time when California's noise element guidelines were cutting edge ideas. But that was 1972. Eight track and Betamax tapes were new then, too. The downside of being an early adopter of any technology is that a shift to still newer technologies necessitates writing off the original investment. The state's guidelines have been little changed since 1972. They date from an era when maps were printed in black and white, and desktop computers didn't exist. Interactive maps such as we see everywhere on the web didn't even show up in science fiction.

Throwing an established governmental program into the garage sale bargain box isn't easy, but the state's obsolete noise mapping requirements are long overdue for an upgrade. It is interesting to speculate why such obviously deficient noise maps weren't trashed years ago. The present guidelines have a certain simple appeal in that drawing up the maps requires little effort or specialized knowledge. The guidelines have been around so long that the text for a noise element and an implementing ordinance is stored on every general plan consultant's word processor. Traffic counts and the old "Sound 32" noise model can be used to figure out how wide to draw the contour lines. It's a simple drafting job to produce the maps. The maps are neither accurate nor easy to understand but they score on the essential points of being easy to produce and on exactly meeting the state's requirements.

\section{Does Noise Matter?}

It's not as if Americans don't consider noise to be a problem. The 2000 Census of Housing included a question that asked people to say whether they were so bothered by street noise that they'd want to move. Of all households surveyed, $4.4 \%$ said they wanted to move. This compares to $3.6 \%$ of all households saying that they were so bothered by crime that they wanted to move. Twice as many households reported that they were impacted by street noise as by crime $(28.2 \%$ vs. $14 \%)$.

The benefits of accurate, accessible and easy to understand noise maps are more than just being a masterpiece of mapping technology. Some people are far more noise sensitive than others. If the community is provided with vivid demonstrations of the differing acoustic environments in a community, people could choose noise settings that fit their preferences. The cost of providing such information is modest compared to the costs of sound walls or residential noise insulation.

The bitterest community noise controversies come about when residents are injected into a noise environment that doesn't meet their expectations. 


\section{Doing the Work}

Technology for making accurate and accessible maps is available, but the question is, "What are the incentives to do this and who pays for the work?"

Like the California plan guidelines, the European initiatives are based on directives that spell out what should be done. The methods and metrics are defined. They also specify that the resulting maps are to be posted on the web. There is also a commitment to what are called Action Plans. These consist of multifaceted programs to improve the noise environment. They identify the number of persons exposed to excessive noise and suggest programs and priorities to reduce the number. They also identify present day quiet zones and provide for their protection. ${ }^{3}$

The first step in any California program to improve the noise environment is to update the antiquated planning guidelines and noise depiction technologies. Some of this is about to be enforced since the Federal Highway Administration now requires use of a new traffic noise model. ${ }^{4}$

Modern day noise modeling software now comes with point and click usability. The availability of digital elevation maps and GIS databases reduces the cost advantages of the handicraft approach. This is particularly so if, as in the European case, the scale of the mapping effort is expanded and analysis is applied across an entire transportation system.

But there's a first order questioning the need to apply high tech noise mapping in every California city. One problem of the one-size-fits-all prescriptions in the Noise Element guidelines is that they don't consider the extreme variability of noise issues. Many California towns are quiet places, without

major industry, freeways, railroads or airports. Certainly these quiet suburbs can have their own noise issues - barking dogs, construction sites, noisy pool pumps and loud parties - but these don't require complex, technical solutions.

More exacting technical analysis is appropriate for towns that are crossed by freeways or that have major airports and industrial facilities. Such noise sources are typically region-serving facilities. The drivers, passengers and workers come from other places.

The European standards attach noise mapping requirements to noise sources instead of to cities. They require noise maps for roadways with more than 16,500 ADT, and for major airports and rail lines. If there were to be a "regional" or "source oriented" approach to noise mapping, who would do it and who would pay for it?

There are economies of scale in dealing with larger regions. The design and the pricing of high quality noise analysis packages such as Cadna $A^{5}$ and SoundPlan ${ }^{6}$ are based on the idea that purchasers will make regular use of the systems. Users require training, as do the specialists in topographic mapping and GIS that deliver the baseline data. There is no need for cities to build such proficiency on their own. The solution is to have noise studies produced through a Service Bureau with the appropriate technology and specialists. In California, Caltrans or a regional transportation planning agency is the appropriate source for organizing such expert assistance. Consulting firms could provide assistance and craft community strategies for dealing with localized noise impacts.

In environmental impact reporting the principal is: "the polluter pays." Noise maps produced for
${ }^{3}$ The text of the EU Environmental Noise Directive (END) can be found at: http://www. ruidos.org/Noise/En_ 32002L0049.html

${ }^{4}$ This is the Traffic Noise Model 2.5 (TNM)

\footnotetext{
${ }^{5}$ www.datakustik. de/download/seiter_6_ CadnaA_E.pdf

${ }^{6}$ http://www.soundplan. com
}

Figure 3

A noise monitoring trailer in Germany.

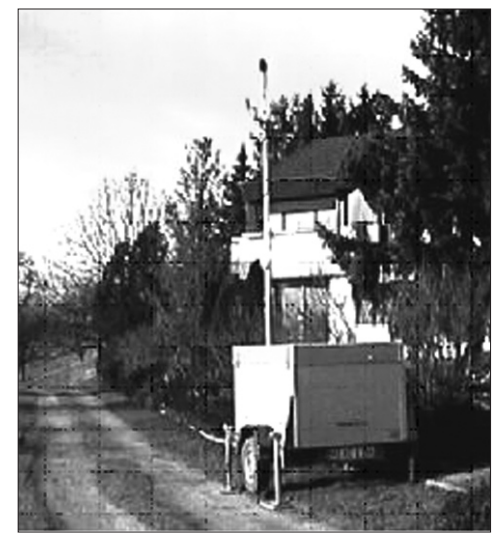




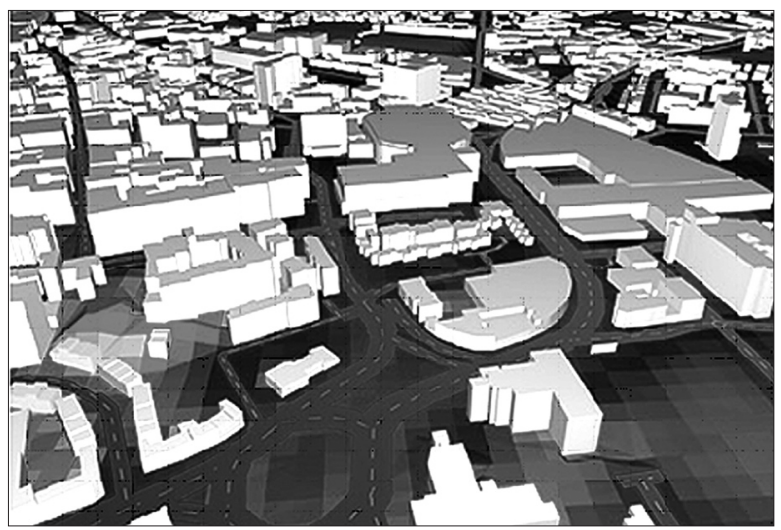

Figure 4

A 3D noise map from the UK (original in colors). commercial airports are typically supported by grants from the FAA - which collects the funds from airline ticket fees. In the case of noise maps for highways, the funding might appropriately come from vehicle license fees or FHWA planning funds. A rate structure might even be established that links vehicle license fees to vehicle noise production (which would be a noise control incentive itself).

When planners advocate Smart Growth and urban infill at higher densities, increasing noise is an authentic concern. The European initiatives provide California with a model of how to craft noise maps that provide accurate and understandable information. Decision makers and people making individual location decisions can benefit from such technologies. The FHWA mandate that requires the use of new noise forecasting technology provides us with an incentive for change. It creates an opportunity to rewrite the tired general plan noise standards that anchor us to the past. We can do better, and in doing better can build a foundation for improving the acoustic environment of our cities. 